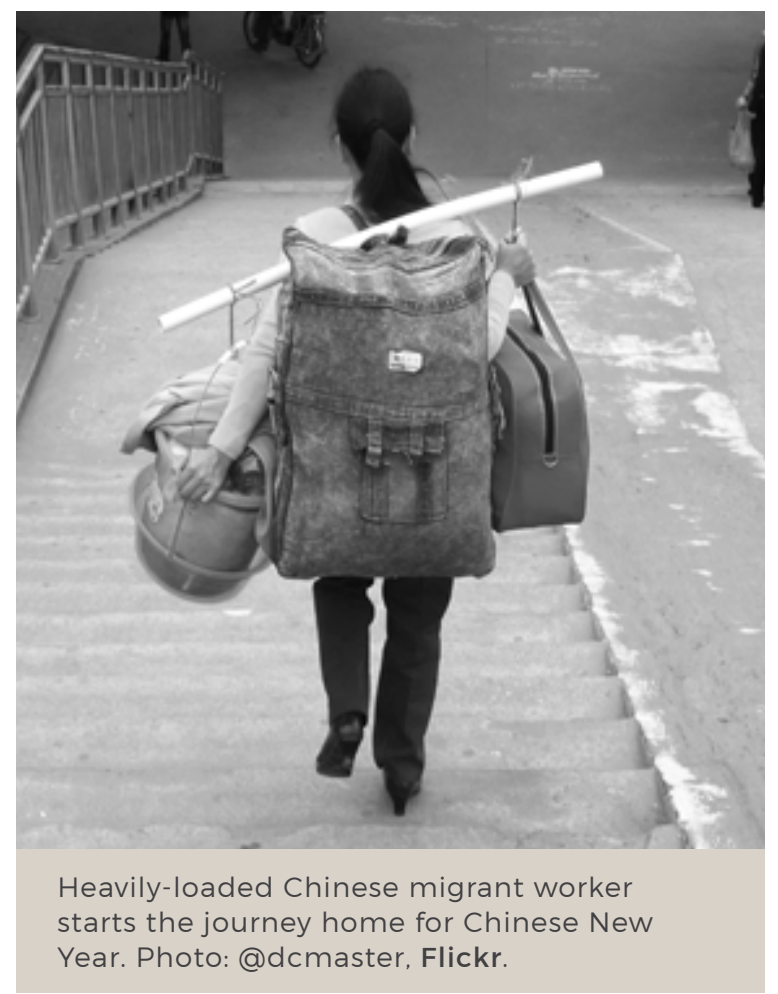

\section{Class and Precarity in China: A Contested Relationship}

\section{Chris Smith Pun Ngai}

The increasing precariousness of labour forces globally has prompted some to argue that a new 'precariat' is emerging to challenge the privileges of the securely employed 'salariat'. This divergence within the working class has been depicted as more significant than the traditional conflict between labour and capital. This essay examines these discussions in China, where precarity is increasingly being employed as a theoretical tool to explain the fragmentation of labour in the country.
There is a general trend in capitalist societies with regard to the nature of employment contracts and relations. The old promise of formal or continuous employment following a probationary period is no longer the norm. It is increasingly harder to get into work, with competitive selection tournaments and rotating internships; and when employed, the length and security of contracts are changing, with zero hour contracts and agency work growing, and direct employment by the firm diminishing for new workers. These trends have prompted some to argue that a new class of precariously employed workers (the precariat) is emerging to challenge the 'privileges' of those who are securely employed. This internal conflict within the working class has been projected as more important than conflicts between labour and capital. This essay looks at these debates in China, where some writers are beginning to apply these ideas to argue that there is a structural bi-furcation in the Chinese working class.

\section{The Precariat Thesis and China}

In his conceptualisation of the rise of precarious work, Guy Standing suggests that internal divisions within the working class, between those in regular/standard employment, judged as being a privileged 'salariat', and those excluded from standard employment contracts, considered as a disadvantaged 'precariat', forms the main 'class divide' in contemporary capitalism. However, as Jane Hardy has pointed out, the problem with arguing that workers on regular jobs 'are a privileged group' is that it 'completely denies the realities of life in the public sector, which has faced commodification, marketization and taken the brunt of austerity.' Looking back at the history of capitalism, well-defined and comprehensive employment security was only 
enjoyed by labour for a relatively short period of time (from the 1950s to the 1970s) and only in advanced economies. In fact, the category of precariat is extremely diverse, including students, temporary and contract workers, elderly workers, migrant and immigrant workforces, as well as workers with very different skill and educational levels. Thus, members of the precariat are defined by their lack of secure contracts. The thesis stresses divisions between the two groups, or empirical examples of collaborations between workers on different contracts. Standing provides no empirical evidence that people in insecure employment identified themselves as part of a separate class. This hints at the fact that 'precariat' is an academic term with little traction in people's lives and selfidentification in class terms.

The employment situation in China follows some of these generic trends, but also has distinctive characteristics that allow close examination of the claim that the precariat is a separate new class. In 2014, China had 772.5 million employed persons, 274 million of whom were rural 'migrant workers' (nongmingong). These migrants are excluded from many basic social benefits because of the country's restrictive household registration system (hukou), which is used by employers to segment workers by different contracts, even though they generally perform similar types of work.

In the case of China, we find that there is a contradictory movement with regard to regular and insecure work. On the one hand, legislation has increased security for regular workers in mass production and mass service industries, where more regular forms of employment have been recognised and protected by law. On the other, the very same legislation has also created incentives for employers to use agency or dispatched workers and bring in non-regular workers. Additionally, many self-employed rural migrants are involved in the informal sector, or are employed in the formal sector but appear to have informal working conditions. Increasingly, urbanised migrant workers continue to be denied equal citizenship and welfare rights, and hold rural hukou in perpetuity. The hukou system 'makes' workers, but not stable urban working class communities. Proletarianisation is separated from urbanisation, and working class community development, which is a typical process in most modernisation projects, is highly fractured in China.

\section{Student Interns, Agency Workers, and Formal Workers}

In a recent attempt to apply the precariat concept to China, Chunsen Yu offers a more detailed empirical assessment of the value of the idea. While we are critical of some of his argument, what his work shows is that the boundary between regular and non-regular work is often crossed. Against a static view of classes of employee, the China case is dynamic and the inflexible concept of the precariat singularly unhelpful. In particular, Yu focuses on the objective conditions of insecurity of rural migrants and uses three indicators of precariat status-non-signing of long-term labour contracts, irregular payments of wages, and non-provision of social security. These conditions are looked at through three elements of 'precariat migrant worker class'student interns, agency workers, and regular workers, which are explored in an empirical study of these workers in seven multinational companies operating in two regions of China: the Liangjiang New Area in Chongqing, and the Longhua and Futian districts in Shenzhen.

In Chongqing the local government promoted 'school-enterprise cooperation' but according to Yu's findings-which contradict official data that says formal workers are the majority of employees-60 percent of the assembly line workers he interviewed were student interns. Reinforcing the findings 
of others, student interns in his sample performed unskilled regular work that bore no relation to their studies. They also worked for less pay, facing the double burden of factory work and school supervision. Yu documents that student interns in Chongqing had no choice but to comply with their schools' internship arrangements with hi-tech factories and other types of manufacturing factories.'

Categorising students as part of the precariat because of their insecure employment means ignoring the major element of their status, i.e. the fact that they are undergoing vocational training and hence work only for the shortterm. Although they often do not receive specialist training in their chosen field, this does not change the fact that they are structurally temporary workers who plan to pursue their career elsewhere. This is a constrained, transitional labour force. $\mathrm{Yu}$ bemoans their lack of commitment to work and the struggle by this section of the socalled precariat, but this is largely due to the abuse of the internship system by colleges and employers, and it is hardly surprising to find members of this group wishing to leave employment that does not match their area of study or their career aspirations.

Due to this mismatch, student interns show a high level of dissatisfaction with factories, and are disengaged with both labour processes and collective action. Yu's research reveals that the majority of his student interns were confused about their identities, as they saw themselves as students, not full-time workers. At the same time, though, they were engaged in hi-tech factories and treated as full-time workers doing assembly line work.

Agency workers face a different set of problems. Working through an agency sets up a triangular relationship between workers and employers. This can add complexity to these relations, as well as fraud, as bogus employment agencies can easily dupe young migrants, taking fees without providing work. Problems can also arise in the event of a labour controversy, as employers and agencies dispute responsibility for health and safety failings. In Yu's research, some companies used a limited number of agencies, generally just the larger ones, while others had a more diverse approach, hiring workers through several commercial labour agencies. Some companies maintained that they offered a temporary-to-permanent pattern of work, with workers having the opportunity to become formal workers after a probationary period, but when Yu spoke to agency workers, they disputed this easy transition. Instead, for them an 'agency labour regime' meant little control over work allocation and schedules, as well as regular reassignments to different types of jobs and easy dismissal.

Still, this and other accounts that stress the negative effects of agencies in forming barriers to secure work ignore the fact that workers possess labour mobility power and they can change agencies if things don't turn out well. Given the large number of agencies in China, there is fierce competition between them for labour, a situation that creates bargaining power for workers. While agencies may try to avoid recruiting workers who change jobs frequently, the high levels of turnover mean this rule is difficult to apply.

Finally, regarding formal workers, while they have regular employment, they also face specific problems. For instance, they are forced to change their jobs frequently, due to factors that include variations in production seasons; the practice of loaning employees (zhiyuan) to other departments or factories; the tradition of changing workers' job specifications and labour relationships (fenliu); as well as an abusive labour regime that involves the use of 'constructive dismissal', active pressure to take on unwanted tasks, and limited job security. Posted workers often lose out financially. For example, enrolment at Foxconn was effectively compulsory, with formal workers being punished with reduced overtime if they did not participate. According to Yu, factories 
routinely violate labour contracts to change formal workers' work, content, and locations, effectively 'selling' labourers from the original factories to other factories or firms.

\section{Problems with the Precariat in China}

The idea central to the precariat thesis, that there is a class divide in terms of the employment conditions of the salariat and precariat, falls at the first hurdle. All workers are insecure in China, and precariousness is not evidence of a separate class, but part of the general condition of waged labour in the country. Take the issue of high labour turnover, seen as indicative of precarity. In fact, labour turnover is high for all groups and in part expresses the mobility power of labourand, as such, it has been a central mechanism for improving wages and conditions. Jobs were more precarious in the 1980 s and the 1990s than in the new millennium when precariousness acquired structural significance. More recent protection, if not standardisation of employment relations, due to state labour policy and legislation, has coincided with more labour resistance and collective actions. More importantly, precarity has been the fate of two generations of migrant workers, but in terms of labour disputes and collective actions, we witness much more in the new or second generation, as indicated by numerous empirical studies. For instance, Pringle notes that in the 2010 dispute at a Honda transmissions factory in Foshan, agency workers were a critical part of the action.

The official categorisation of peasant workers-wage labourers with rural household registration-keeps their social status and class identities ambiguous. Taking a specific path of proletarianisation, the new generation of migrant workers has gradually become aware of their class position and participated in a series of collective actions.
The migrant workers are now experiencing a deeper sense of anger and dissatisfaction than that of the first generation, accompanied by the realisation that the return to their hometowns is more problematic.

To conclude, precariousness as a process is a useful concept, 'precariat' is not. At different times, precariousness is a more or less important attribute of being a worker. The idea that security is fixed and settled is unhelpful as is the idea of a new class called the 'precariat'. The processes of creating non-standard forms of employment are recognisable across work with different forms of status, from unskilled to more white collar and professional occupations. More importantly, we need to look at interactions between workers on different contracts in production relations, and not invent employment differences that confuse employment status and social class. Class is about ownership relations, and structural class relations between labour and capital.

\section{Chris Smith}

Chris Smith is Professor of Organisation Studies and Comparative Management at Royal Holloway, University of London. His research interests are in labour process theory, work and employment transfer through the transnational firm, comparative analysis of work and employment, and professional labour.

\section{Pun Ngai}

Pun Ngai is a Professor in the Department of Sociology at the University of Hong Kong. Her research focusses on labour, gender, and globalisation in mainland China and Hong Kong. She has published extensively in the areas of sociology, anthropology, labour studies, China studies, and cultural studies. 